\title{
Corticosteroid treatment as a risk factor for invasive aspergillosis in patients with lung disease
}

\author{
Lucy B Palmer, Harly E Greenberg, Mark J Schiff
}

\begin{abstract}
Invasive pulmonary aspergillosis usually occurs in severely immunocompromised or neutropenic patients. Six patients with invasive aspergillosis are described whose only defence impairment was underlying lung disease and corticosteroid treatment. Cough, fever, and sputum production were the usual reasons for presentation and four patients developed the sepsis syndrome. Radiographic findings included de novo cavitation in three patients and rapid radiographic progression in four. Aspergillus species were isolated from respiratory secretions of all patients early in the course of the disease. Treatment was effective in only two patients and the subsequent progress of the others was consistent with a chronic necrotising process. Invasive pulmonary aspergillosis is uncommon in patients with respiratory diseases receiving corticosteroids, but should be considered when pneumonia and cavitary infiltrates occur.
\end{abstract}

Invasive pulmonary infection with Aspergillus fumigatus usually occurs in severely immunocompromised individuals receiving high dose corticosteroids or cytotoxic chemotherapy, or in those with prolonged neutropenia. ${ }^{12}$ The risk of the disease in patients with haematological malignancies receiving chemotherapy is well known. We report six patients with lung cancer or other lung disease who developed invasive pulmonary aspergillosis. They were not receiving chemotherapy and were not neutropenic. Their common risk factor was corticosteroid treatment.

\section{Patients and methods}

Patients were included in this study if they had either a tissue diagnosis confirming invasive pulmonary aspergillus infection or, when tissue could not be obtained, respiratory secretions from which Aspergillus was cultured and a clinical history and radiographic or computed tomography findings highly suggestive of invasive disease-for example de novo cavitation with subsequent mycetomas. Patients with lymphoma or leukaemia and those receiving immunosuppressive drugs other than corticosteroids were excluded. Bronchoscopic specimens were obtained by lavaging the segment that was worst affected radiologically with $100 \mathrm{ml}$ of normal saline. Transbronchial biopsy was possible in only two patients. Fungal cultures were made on Sabaroud-dextrose agar.

Patients had been managed at different times and in locations in the hospital, and no common environmental exposure was identified. Five of the cases are described in detail; case 6 has been reported previously. ${ }^{3}$

\section{Case reports}

PATIENT 1

A 75 year old white woman presented with chills, fever $\left(38.4^{\circ} \mathrm{C}\right)$, increased cough and purulent sputum. Six weeks earlier, when she was admitted with a chronic cough, chest radiography had shown bilateral interstitial infiltrates, spirometry a restrictive pattern, and transbronchial biopsy pronounced interstitial fibrosis consistent with idiopathic pulmonary fibrosis. She was discharged taking prednisone $40 \mathrm{mg} /$ day and antibiotics.

On readmission, she had a tachycardia and bilateral coarse rhonchi, and the chest radiograph showed left lower lobe consolidation. The white blood count was $18.3 \times 10^{9} / 1$ (83\% neutrophils, $8 \%$ band forms) and a Gram stained sputum smear showed neutrophils with Gram positive and Gram negative rods. Cefuroxime and gentamicin were given intravenously and the corticosteroid dose was increased. Increasing dyspnoea and sudden severe right sided chest pain prompted pulmonary angiography three days after admission but no intraluminal thromboemboli were seen. Progressive hypoxaemia with worsening left lower lobe consolidation led to intubation and assisted ventilation. Bronchoalveolar lavage showed Aspergillus fumigatus. Amphotericin B was started on the fifth day after admission but she continued to deteriorate and died two days later.

At necropsy there was extensive necrosis of the left upper lobe and right and left lower lobes. Aspergillus sp was found within the parenchyma and bronchial lumen, particularly in the left upper and lower lobes. Interstitial fibrosis was evident in the right lung. Postmortem lung and blood cultures revealed Aspergillus fumigatus.

\section{PATIENT 2}

A 76 year old white man with bronchoalveolar carcinoma presented with three episodes of haemoptysis. Two years earlier he had had a right upper lobectomy for localised bronchoalveolar carcinoma. When cerebral metastases 


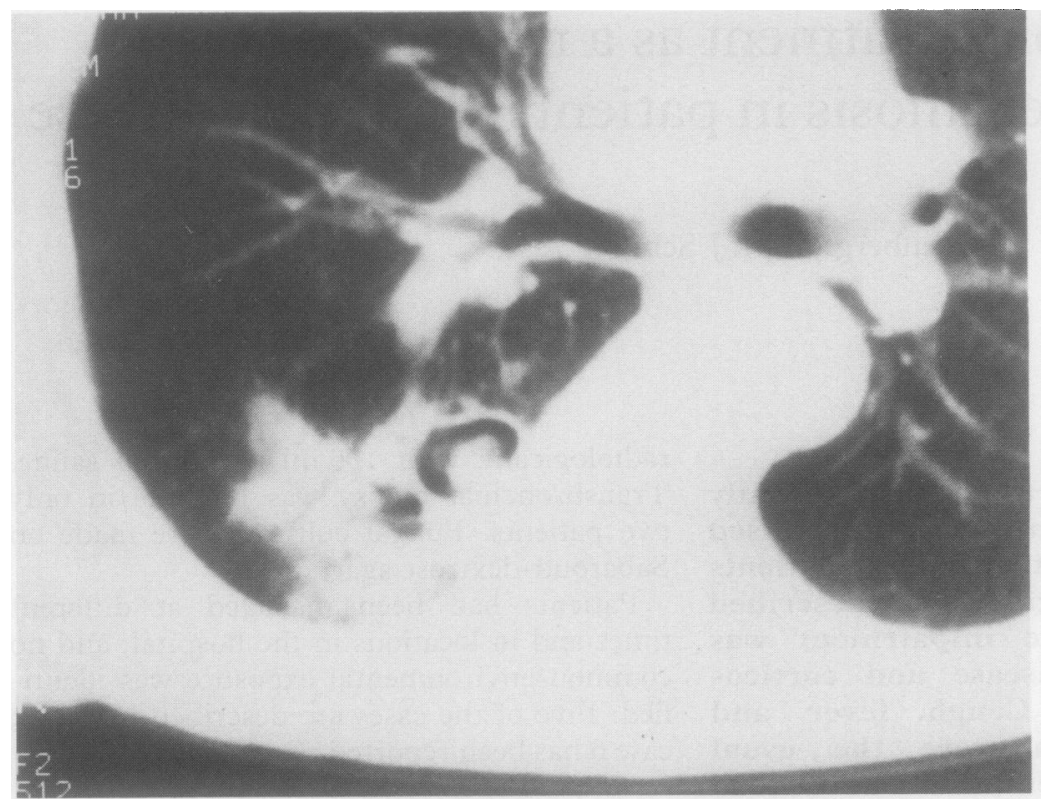

Figure 1 Computed tomogram from patient 2 showing an intracavitary mass consistent with mycetoma.

were found four months before his admission to hospital he received radiotherapy and dexamethasone $4 \mathrm{mg}$ four times daily.

For four days before admission he had recurrent daily haemoptysis. On admission there were a few rhonchi in the right lung but the chest radiograph was normal. At bronchoscopy inflamed mucosa was noted on the right and culture of bronchial lavage fluid yielded Aspergillus sp. Bronchial biopsy showed minimal inflammation. As the chest radiograph was normal the Aspergillus was considered to be a saprophyte colonising the lung, so treatment with trimethoprimsulphamethoxazole was started for presumed bronchitis. Six days later the haemoptysis recurred. Radiography showed a right lower lobe infiltrate and computed tomography cavitating lesions in the right lower lobe with bronchiectasis and an intracavitary mass (fig 1). Amphotericin B was started as further attempts to obtain a tissue diagnosis were not considered appropriate. Repeat computed tomography after $1 \mathrm{~g}$ of amphotericin B showed resolution of much of the infiltrate but persistence of the cavity and the formation of a new cavity in the right lower lobe. The patient received an additional gram of amphotericin $\mathbf{B}$ and improved clinically with resolution of the infiltrate.

\section{PATIENT 3}

A 30 year old black man had presented three years earlier with stage II sarcoidosis with severe lung and skin disease that required continuous treatment with varying doses of prednisone-most recently $20 \mathrm{mg} /$ day. Three

Clinical data on the six patients

\begin{tabular}{|c|c|c|c|c|c|c|}
\hline Patient No & 1 & 2 & 3 & 4 & 5 & $6^{\star}$ \\
\hline Age, sex & $75, \mathrm{~F}$ & $76, M$ & $30, \mathrm{M}$ & $63, M$ & $74, M$ & $74, \mathrm{M}$ \\
\hline $\begin{array}{l}\text { Underlying } \\
\text { disease }\end{array}$ & $\begin{array}{l}\text { Idiopathic } \\
\text { pulmonary } \\
\text { fibrosis }\end{array}$ & $\begin{array}{l}\text { Lung cancer, } \\
\text { non-small cell } \\
\text { CNS } \\
\text { metastases }\end{array}$ & Sarcoidosis & $\begin{array}{l}\text { Lung cancer, } \\
\text { small cell }\end{array}$ & $\begin{array}{l}\text { Lung cancer, } \\
\text { non-small cell; } \\
\text { radiation } \\
\text { pneumonitis }\end{array}$ & $\begin{array}{l}\text { Chronic obstructive } \\
\text { lung disease }\end{array}$ \\
\hline $\begin{array}{c}\text { Steroid dose, } \\
\text { duration of } \\
\text { treatment }\end{array}$ & $\begin{array}{l}\text { Prednisone: } 40 \\
\mathrm{mg} / \mathrm{d} \times 6 \mathrm{wk}\end{array}$ & $\begin{array}{l}\text { Dexamethasone: } \\
16 \mathrm{mg} / \mathrm{d} \times 4 \\
\text { mo }\end{array}$ & $\begin{array}{l}\text { Prednisone: } 20- \\
\quad 40 \mathrm{mg} / \mathrm{d} \times 3 \mathrm{y}\end{array}$ & $\begin{array}{l}\text { Dexamethasone: } \\
24 \mathrm{mg} / \mathrm{d} \\
\text { tapered to } 8 \\
\mathrm{mg} / \mathrm{d} \times 1 \mathrm{mo}\end{array}$ & $\begin{array}{l}\text { Prednisone: } 30 \\
\mathrm{mg} / \mathrm{d} \times 3 \mathrm{wk}\end{array}$ & $\begin{array}{l}\text { Prednisone: } 10-30 \\
\mathrm{mg} / \mathrm{d}\end{array}$ \\
\hline $\begin{array}{l}\text { Amphotericin } \\
\text { treatment }\end{array}$ & + & + & + & & & + \\
\hline $\begin{array}{l}\text { Sputum or lavage } \\
\text { fluid culture }\end{array}$ & $\begin{array}{l}\text { BAL: Aspergillus } \\
\quad \text { fumigatus }\end{array}$ & BAL: A fumigatus & $\begin{array}{l}\text { BAL, sputum: } \\
\text { Aspergillus sp }\end{array}$ & $\begin{array}{l}\text { Sputum: } \\
\text { Aspergillus sp }\end{array}$ & $\begin{array}{l}\text { Sputum: } \\
\text { Aspergillus sp }\end{array}$ & $\begin{array}{l}\text { Sputum: Aspergillus } \\
\text { sp }\end{array}$ \\
\hline $\begin{array}{l}\text { White blood } \\
\text { count }\left(\times 10^{9} / 1\right)\end{array}$ & $18 \cdot 3$ & $14 \cdot 9$ & $35 \cdot 0$ & $6 \cdot 8$ & $19 \cdot 5$ & 33.6 \\
\hline Chest radiograph & Diffuse infiltrates & $\mathrm{RML}$ infiltrate & $\begin{array}{l}\text { RUL cavity } \\
\text { RUL, LLL } \\
\text { infiltrates }\end{array}$ & $\begin{array}{r}\text { RUL, LUL } \\
\text { infiltrates }\end{array}$ & $\begin{array}{l}\text { RUL cavity, air- } \\
\text { fluid level; } \\
\text { RUL, LLL } \\
\text { infiltrates }\end{array}$ & RUL infiltrate \\
\hline $\begin{array}{l}\text { Necropsy, lung } \\
\text { histology, } \\
\text { culture }\end{array}$ & $\begin{array}{l}\text { Necrotising } \\
\text { pneumonitis } \\
\text { with Aspergillus }\end{array}$ & - & $\begin{array}{l}\text { Mycetoma with } \\
\text { Aspergillus; } \\
\text { fungal culture } \\
\text { negative } \\
\text { Pseudomonas } \\
\text { aeruginosa }\end{array}$ & $\begin{array}{l}\text { Necrotising } \\
\text { pneumonitis } \\
\text { with Aspergillus }\end{array}$ & $\begin{array}{l}\text { Necrotising } \\
\text { pneumonitis } \\
\text { with Aspergillus }\end{array}$ & $\begin{array}{l}\text { Necrotising } \\
\text { pneumonitis with } \\
\text { Aspergillus }\end{array}$ \\
\hline $\begin{array}{l}\text { Time from } \\
\text { symptom onset } \\
\text { to diagnosis or } \\
\text { death }\end{array}$ & 2 weeks & 1 month & 3 weeks & 7 days & 3 months & 8 days \\
\hline Outcome & Death & $\begin{array}{l}\text { No active } \\
\text { aspergillosis }\end{array}$ & Death & Death & Death & Death \\
\hline
\end{tabular}

CNS—central nervous system; BAL—bronchoalveolar lavage fluid; RML—right middle lobe; RUL—right upper lobe; LLL—left lower lobe; LUL—left upper 

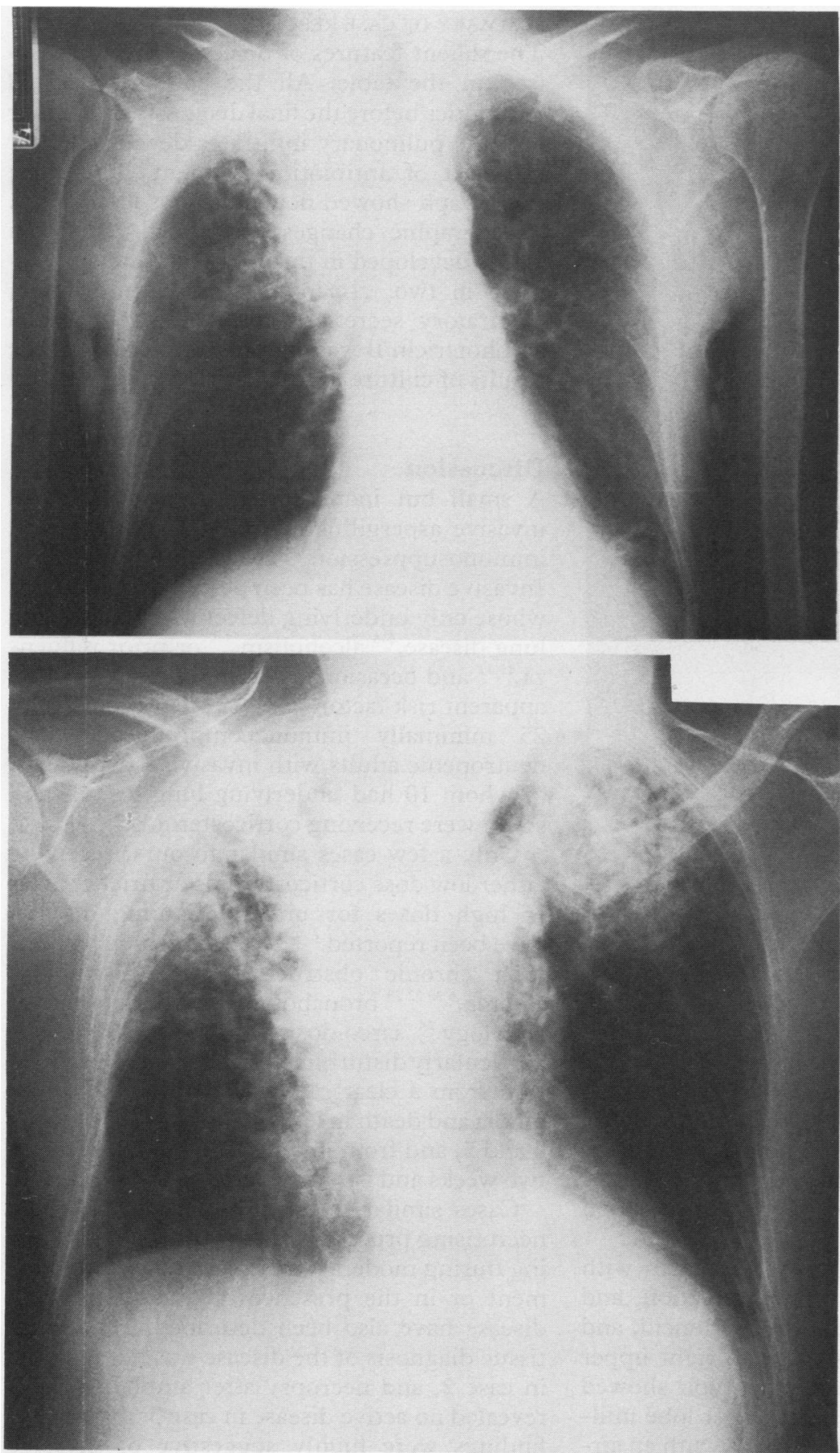

Figure 2 Chest radiographs from patient 4 showing the rapid progression of pneumonia to bilateral lesions over five days.

weeks before the present admission a cough with purulent sputum and low grade fever was treated with several antibiotics without response. On admission he had the same symptoms plus right sided pleuritic chest pain. The chest radiograph showed bilateral hilar lymphadenopathy, diffuse interstitial infiltrates, and a new right upper lobe cavity with a surrounding infiltrate. Cefuroxime was begun and prednisone continued. Computed tomography confirmed the right upper lobe cavity and surrounding infiltrate and showed an intracavitary mass suggesting an aspergilloma. Culture of sputum and bronchoalveolar lavage fluid and a bronchial brushing revealed Aspergillus sp. Amphotericin B treatment was begun for presumed chronic invasive aspergillosis. Gradual defervescence occurred over the following three weeks. The patient received $1.5 \mathrm{~g}$ of amphotericin $\mathrm{B}$ as an outpatient.

Three weeks later fever, cough, and sputum production recurred. At admission there was fever $\left(39^{\circ} \mathrm{C}\right)$ and hypotension, and hypoxaemic respiratory failure necessitated assisted ventilation. The chest radiograph showed a new right upper and left lower lobe consolidation and a Gram stained sputum smear showed numerous Gram negative rods. Despite ticarcillin with clavulanate sodium, gentamicin, fluids, and vasopressors the patient died after a few hours.

At necropsy there was extensive destruction of the parenchyma of the upper lobes with cavitation. The cavities contained mycetoma mixed with necrotic lung tissue. Histological examination of the cavity contents showed Aspergillus sp, though culture was negative, suggesting non-viable organisms. No direct pulmonary invasion was observed. Extensive consolidation and multiple small abscesses were also noted throughout the lungs. Postmortem lung cultures showed Pseudomonas aeruginosa. The apparent cause of death was Gram negative sepsis and respiratory failure.

\section{PATIENT 4}

A 63 year old white man with small cell carcinoma of the lung presented with rapidly progressive radiographic infiltrates. When he had presented two years earlier with a right upper lobe mass, a mediastinal mass, and occlusion of the superior vena cava, biopsy showed small cell carcinoma. He was treated with radiotherapy and six cycles of chemotherapy, completed six weeks before admission. One month before admission the patient presented with symptoms and magnetic resonance images were consistent with T6-8 cord compression, so he was started on dexamethasone $4 \mathrm{mg}$ every 12 hours and local radiotherapy. The corticosteroids were increased to $24 \mathrm{mg} /$ day and then reduced to $4 \mathrm{mg}$ twice daily over one month.

On admission he complained of progressive weakness and decreased appetite. The white blood cell count was $3.1 \times 10^{9} / 1$ (52\% neutrophils, $30 \%$ bands, $14 \%$ monocytes, $14 \%$ eosinophils). A chest radiograph showed a right paratracheal mass and infiltrate (fig $2 a$ ) and the patient was started on cefoxitin and gentamicin for presumed sepsis. Ten days later he was increasingly short of breath and a chest radiograph showed rapid progression of the infiltrate (fig $2 b$ ). The white cell count was $6.8 \times 10^{9} / 1$ with $68 \%$ neutrophils, $21 \%$ bands, $10 \%$ lymphocytes, and $1 \%$ atypical lymphocytes. He refused further treatment and died the next day. Sputum cultures showed Aspergillus fumigatus.

Postmortem examination disclosed no residual carcinoma, but there was extensive necrosis and cavitation within the mediastinum and right and left lung, with Aspergillus hyphae throughout these areas. Cultures of the lung revealed $A$ fumigatus. 


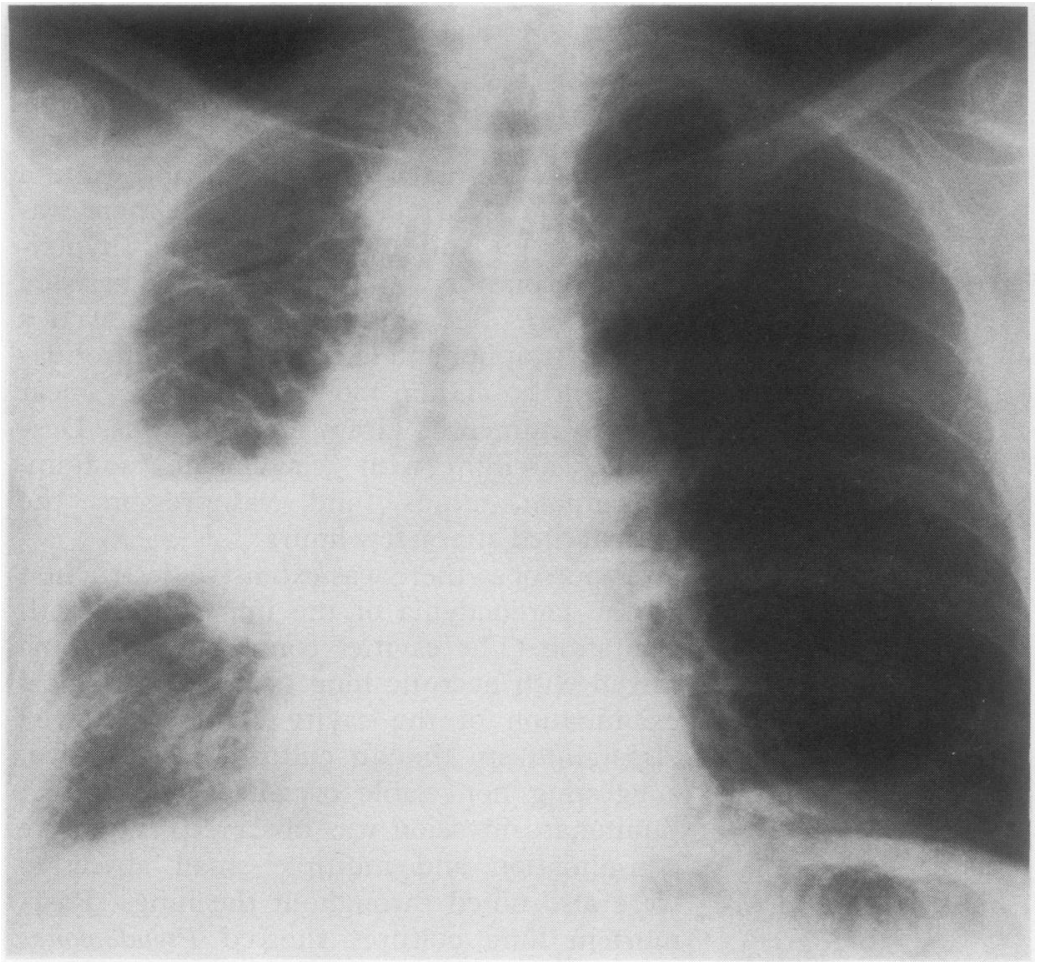

Figure 3 Chest radiograph from patient 5 showing cavitary pneumonia in the right upper lobe.
SUMMARY OF CASE REPORTS

The salient features of our cases are summarised in the table. All the patients received antibiotics before the final diagnosis and in four patients pulmonary infiltrates developed after the start of antibiotic treatment. The chest radiograph showed new infiltrates in all cases. Radiographic changes progressed rapidly; a cavity developed in three patients and a mycetoma in two. Aspergillus was cultured from respiratory secretions from all patients and amphotericin B was started on the basis of the results of culture in four cases.

\section{Discussion}

A small but increasing number of cases of invasive aspergillus in patients with minimal immunosuppression have been reported. ${ }^{4-27}$ Invasive disease has been described in patients whose only underlying defect was pre-existing lung disease, ${ }^{4-6}$ alcoholism, ${ }^{7-9}$ or prior influen$\mathrm{za}^{10}{ }^{11}$ and occasionally in individuals with no apparent risk factor. ${ }^{412-18} \mathrm{~A}$ recent report cited 25 minimally immunocompromised, nonneutropenic adults with invasive aspergillosis, of whom 10 had underlying lung disease and seven were receiving corticosteroids. ${ }^{4}$

Only a few cases similar to ours, receiving either low dose corticosteroids or brief courses of high doses for underlying lung disease, have been reported. ${ }^{619-26}$ They include patients with chronic obstructive lung disease, ${ }^{19-21}$ asthma, ${ }^{602223}$ bronchospasm of undetermined aetiology, ${ }^{24}$ sarcoidosis, ${ }^{25}$ and berylliosis. ${ }^{26} \mathrm{~A}$ particularly disturbing feature was the progression from a clear radiograph to severe pneumonia and death in less than 10 days in patients 4 and 5 , and from initial symptoms to death in two weeks and two months in patients 1 and 6 .

Cases similar to ours with a more chronic necrotising process (patients 2 and 3 ) developing during moderate dose corticosteroid treatment or in the presence of underlying lung disease have also been described. ${ }^{28}$ Although tissue diagnosis of the disease was not possible in case 2, and necropsy after amphotericin B revealed no active disease in case 3 , the clinical findings were highly suggestive of invasive disease. In both cases the computed tomography findings were consistent with de novo cavitation and mycetoma formation, as previously reported. ${ }^{29} 30$

The development of invasive aspergillosis during long term treatment with low dose corticosteroids or short term treatment with higher doses raises the question of how corticosteroids affect the establishment of invasive parenchymal disease. The specific immune defences against $A$ spergillus are not fully delineated but appear to include both macrophages and neutrophils. ${ }^{3132}$ The response to inhaled conidia of Aspergillus is different from the mechanism controlling hyphal growth in tissue. Animal studies suggest the former activity to be mediated by macrophages and hyphal killing by polymorphonuclear cells. ${ }^{31} 32$ The presence of either means of defence appears to be sufficient, at least in animal models. Glucocorticoids suppress the migrainvasive aspergillosis with extensive necro the right lung and acute necrotising tracheobronchitis. No residual carcinoma or obstructing lesion was found. Culture showed Aspergillus and Pseudomonas maltophila. 
tion of phagocytes and decrease the antifungal activity of monocytes and tissue macrophages as well as altering cell mediated immunity. ${ }^{33-36}$ In animal studies cortisone inhibits the conicidal activity of macrophages both in vitro and in vivo. Macrophage antifungal activity was suppressed in vitro at doses as low as $9 \mathrm{ng} / \mathrm{ml}$ of dexamethasone or $100 \mathrm{ng} / \mathrm{ml}$ of cortisone ${ }^{33}$ (physiological level 8-220 ng of cortisone over 24 hours with free cortisol concentrations of $\left.0.8-28 \mathrm{ng} / \mathrm{ml}^{37}\right)$. In vivo studies have shown a minimal neutrophil response to invasive aspergillus disease in animals treated with corticosteroids. ${ }^{31}$ The dose of corticosteroids causing failure of these defences in patients appears to depend on many host factors. Attempts to establish a threshold level of corticosteroid that puts patients at high risk for infection have been made in specific groups of patients. In patients receiving corticosteroids after renal transplantation the best predictor of infection was a daily dose greater than $1.25 \mathrm{mg} / \mathrm{kg}$ of prednisone. ${ }^{38}$ In patients with liver transplants the total number of corticosteroid boluses had the best correlation with fungal infection. ${ }^{39}$ Cases like our own suggest that with underlying lung disease the risk occurs at much lower doses and fungal growth may be as explosive as that seen in patients with haematological disorders.

The first indication of infection in our patients was a positive culture from respiratory tract secretions, confirming an earlier report. ${ }^{4}$ Potassium hydroxide preparations at the time of obtaining samples were not done. With saprophytic infestation conidiophores with conidia bearing vesicles should be seen. ${ }^{40}$ Their presence, however, would not exclude distal invasive infection. The finding of hyphal elements when secretions are first examined does eliminate the possibility of contamination of secretions with spores and suggests invasion, but is not a substitute for the finding of hyphae in tissue as confirmation of the diagnosis. The clinical meaning of Aspergillus on smears or cultures of pulmonary secretions is frequently not clear. Aspergillus grew in cultures of sputum from $6-16 \%$ of patients with chronic obstructive lung disease and normal hosts. ${ }^{41}{ }^{42}$ Positive bronchial lavage cultures appear to indicate infection more specifically, but their sensitivity has not been established. ${ }^{43}$ In the setting of pneumonia in neutropenic patients the culture of Aspergillus in any respiratory secretion should lead to prompt investigation if there is any suspicion of invasive disease. ${ }^{44}$ Our results suggest this is also true in patients with lung disease.

Corticosteroids, in the doses our patients received, are used frequently in patients with asthma, chronic obstructive lung disease, interstitial lung disease, radiation pneumonitis, and various non-pulmonary disorders. The risk of opportunist infections in such settings is probably quite low, but should be considered when decisions are being made about the dose and duration of corticosteroid treatment. Aspergillus should be included in the differential diagnosis of pneumonia or cavitary infiltrates in such patients and the finding of
Aspergillus in their respiratory secretions should not be dismissed as colonisation.

1 Herbert PA, Bayer AS. Fungal pneumonia: invasive pulmonary aspergillosis (Part 4). Chest 1981;80:220-5.

2 Young RC, Bennet JE, Vogel CL, Carbone PP, Devita VT Aspergillosis: the spectrum of disease in 98 patients. Medicine (Baltimore) 1970;49:147-73.

3 Palmer LB, Schiff MJ. Rapidly progressive pneumonia in a patient with chronic obstructive pulmonary disease. Chest 1989;95:179-80.

4 Karam GH, Griffin FM. Invasive pulmonary aspergillosis in non-immunocompromsed, non-neutropenic hosts. Rev Infect Dis 1986;8:357-63.

5 Roselle GA, Kaufman CA. Invasive pulmonary aspergillosis in a non-imnunocompromised patient. $\mathrm{Am} \mathrm{J} \mathrm{Med} \mathrm{SCi}$ 1978;276:357-iil

6 Kallenbach J, Lusheiko J, Block CS, Bethlehem B Koornhof $\mathrm{HJ}$, Zwi S. Aspergillus pneumonia-a cluster of four cases in an intensive care unit. $S$ Afr Med 1977;52:919-23.

7 Blum J, Reed JC, Pizzo SV, Thompson WM. Miliary aspergillosis associated with alcoholism. Am J Radio 1978;131:707-9.

8 Zellner SR, Selby JB, Loughrin JJ. Aspergillosis. Am Rev Respir Dis 1969;100:217-20.

9 Sawkar LA, Dickerman JM, Easom HF. Primary pulmonary aspergillosis. $N C$ Med 1972;33:776-8.

10 Mcleod DT, Milne LJR, Seaton A. Successful treatment of invasive pulmonary aspergillosis complicating influenza A. Br Med J 1982;285:1166-7.

11 Fischer JJ, Walker DH. Invasive pulmonary aspergillosis associated with influenza. JAMA 1979;241:1493-4.

12 Strelling MK, Rhaney K, Simmons DAR, Thomson J. Fatal acute pulmonary aspergillosis in two children of a family. Arch Dis Child 1966;41:34-43.

13 Grcevic N, Matthews WF. Pathologic changes in acute disseminated aspergillosis: particularly involvement of the central nervous system. Am J Clin Pathol 1959;32:536-51.

14 Pelczar ME, Glas-Greenwalt P, Astrup T. Primary pulmonary aspergillosis with high fibrinolytic activity in the aortic intima. Chest 1972;61:394-6.

15 Schrijver G, Verwers HR, Meinders AE. A nonimmunosuppressed patient with presumably invasive pulmonary aspergillosis and a favorable outcome. Neth J Med 1983; 26:112-9.

16 Brown E, Freedman S, Arbeit R, Come S. Invasive pulmonary aspergillosis in an apparently nonimmunocompromised host. Am J Med 1980;69:624-7.

17 Cooper JAD, Weinbaum DL, Aldrich TK, Mandell GL. Invasive aspergillosis of the lung and pericardium in a nonimmunocompromised 33 year old man. $A m \mathrm{~J} \mathrm{Med}$ 1981;71:903-7.

18 Emmons RW, Able ME, Tenenberg DJ, Schacter J. Fatal pulmonary psittacosis and aspergillosis. Arch Intern Med 1980;140:697-8.

19 Tankanow L, Eichenhorn MS. Disseminated Strongyloides stercoralis and Aspergillus fumigatus presenting as diffuse interstitial pneumonitis in a steroid-dependent chronic obstructive pulmonary disease patient. Henry Ford Hosp Med J 1988;36:41-3.

20 Ordronneau J, de Lajartre AY, Chollets S, Germaud P, Moinard D, Chailleux E. Aspergillosé invasive disseminée associee a une infection a Mycoplasma pneumoniae. Rev Mal Respir 1987;4:273-5.

21 West PM, Flanagan T, Salata RA, Shlaes DM, Katzman M, Lederman MM. Serious infectious complications of corticosteroid therapy for COPD. Chest 1989;95:1180-4.

22 Rodfuhuis S, Beaumont F, Kauffman HF, Sluiter HJ Invasive pulmonary aspergillosis in a non-immunosuppressed patient: successful management with systemic amphotericin and flucytosine and inhaled amphotericin. Thorax 1984;39.78-9.

23 Lake KB, Browne PM, Van Dyke JJ, Ayers L. Fatal disseminated aspergillosis in an asthmatic patient treated with corticosteroids. Chest 1983;83:138-9.

24 Weiss LM, Thiemke WA. Disseminated Aspergillus ustus infection following cardiac surgery. Am J Clin Pathol 1983;80:408-11.

25 Waldhorn RE, Tsou E, Kerwin DM. Invasive pulmonary aspergillosis associated with aspergilloma and sarcoidosis. South Med J 1983;76:251-3.

26 O'Brien AAJ, Moore DP, Keogh JAB. Pulmonary berylliosis on corticosteroid therapy with cavitating lung lesions and aspergillomata-report on a fatal case. Postgrad Med J 1987;63:797-9.

27 Karas A, Hankins JR, Attar S, Miller JE, McLaughlin JS. Pulmonary aspergillosis: an analysis of 41 patients. $A n n$ Thorac Surg 1976;22:1-7.

28 Binder RE, Faling JL, Pugatch RD, Mahasaen C, Snider GL. Chronic necrotizing pulmonary aspergillosis: a GL. Chronic necrotizing pulmonary aspergillosis: a
discrete clinical entity. Medicine (Baltimore) 1982;61: discrete

29 Meyer RD, Young SY, Armstrong D, Yu B. Aspergillosis 
complicating neoplastic disease. Am J Med 1973;54:6-15 30 Burke PS, Coltman CA. Multiple pulmonary aspergilloma in acute leukemia. Cancer 1971;28:1289-92.

31 Schaffner A, Douglas H, Braude A. Selective protection against conidia by mononuclear and against mycelia by polymorphonuclear phagocytes in resistance to aspergillus. J Clin Invest 1982;69:617-31.

32 Waldorf AR, Levitz SM, Diamond RD. In vivo bronchoalveolar macrophage defense against Rhizopus oryzae and Aspergillus fumigatus. J Infect Dis 1984;150:752-60.

33 Fauci AS, Dale DC, Balow JE. Glucocorticoid therapy: mechanisms of action and clinical considerations. An Intern Med 1976;84:304-15.

34 Rinehart JJ, Sagone AL, Balcersak SP, Ackerman GA Lobuglio AF. Effects of corticosteroids therapy on human monocyte function. N Engl J Med 1975;292:236-41.

35 Rinehart JJ, Balcersak SP, Lobuglio AF. Effects of corticosteroids on human monocyte function. J Clin Invest 1975

36 Schaffner A. Therapeutic concentrations of glucocorticoids suppress the antimicrobial activity of human macrophages without impairing their responsiveness to gamma interferon. $J$ Clin Invest 1985;76:1755-64.

37 Baumann G, Rappaport G, Lemarchand-Beraud T, Felber JP. Free cortisol index: a rapid and simple estimation of free cortisol in human plasma. $J$ Clin Endocrinol Metab 1975;40:462-9.

38 Gustafson TL, Schaffner W, Lavely GB, Stratton CW, Johnson HK, Hutcheson RH. Invasive aspergillosis in renal transplant recipients: correlation with corticosteroid therapy. J Infect Dis 1983;148:236-8.

39 Wajszczuk CP, Dummer JS, Ho M, et al. Fungal infection in liver transplant recipients. Transplantation 1985;40: $347-53$.

40 Rippon JW. Medical mycology. London: Saunders, 1988: $618-50$.

41 Pepys J, Riddel R, Citron K, Clayton Y, Short E. Clinical and immunologic significance of Aspergillus fumigatus in the sputum. Am Rev Respir Dis 1959;80:167-72.

42 Comstock GW, Palmer CE, Stone RW, Goodman NL. Fungi in the sputum of normal men. Mycopathol Mycol Appl 1974;54:55.

43 Stover DE, Zaman MB, Hajdu SL, Lange M, Gold J, Armstrong D. Bronchoalveolar lavage in the diagnosis of diffuse pulmonary infiltrates in the immunocompromised host. Ann Intern Med 1984;101:1-7.

$44 \mathrm{Yu}$ VL, Muder RR, Poorsattar A. Significance of isolation of Aspergillus from the respiratory tract in diagnosis of invasive pulmonary aspergillosis. Am J Med 1986;81: 249-54 